Materials Researchers

\section{Caltech names \\ Thomas F. Rosenbaum as new president}

T homas F. Rosenbaum was named as the ninth president of the California Institute of Technology (Caltech) in October. Rosenbaum will succeed Jean-

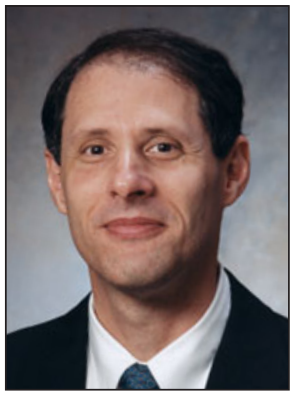

Lou Chameau,

who served the Institute from 2006 to 2013 , and will take over the helm from interim president and provost Ed Stolper on July 1, 2014.

Rosenbaum is currently the John T. Wilson Distinguished Service Professor of Physics at the University of Chicago, where he has served as the university's provost for the past seven years. As a distinguished physicist and expert on condensed-matter physics, Rosenbaum has explored the quantum mechanical nature of materials, making major contributions to the understanding of matter near absolute zero, where such quantum mechanical effects dominate. His experiments in quantum phase transitions in matter are recognized as having played a key role in placing these transitions on a theoretical level equivalent to that which has been developed for classical systems.

The Caltech Faculty Search Committee, chaired by Fiona Harrison, and the Trustee Selection Committee, chaired by David Lee, worked together on the presidential search. Harrison said that Rosenbaum "is a first-rate scholar and someone who understands at a deep level the commitment to fundamental inquiry that characterizes Caltech. He is also the kind of ambitious leader who will develop the faculty's ideas into the sorts of innovative ventures that will maintain Caltech's position of prominence in the next generation of science and technology."
"The combination of deep management experience and visionary leadership Tom brings will serve Caltech extremely well in the coming years," Lee said.

Rosenbaum received his bachelor's degree in physics with honors from Harvard University in 1977, and MA and $\mathrm{PhD}$ degrees in physics from Princeton University in 1979 and 1982, respectively. He did research at Bell Laboratories and at IBM Watson Research Center before joining the University of Chicago's faculty in 1983. Rosenbaum directed the university's Materials Research Laboratory from 1991 to 1994 and its interdisciplinary James Franck Institute from 1995 to 2001 before serving as vice president for research and for Argonne National Laboratory from 2002 to 2006 . He was named the university's provost in 2007.

His honors include an Alfred P. Sloan Research Fellowship, a Presidential Young Investigator Award, and the William McMillan Award for "outstanding contributions to condensed matter physics." Rosenbaum is an elected Fellow of the American Physical Society, the American Association for the Advancement of Science, and the American Academy of Arts and Sciences.

\section{Rod Ewing named Frank Stanton Professor in Nuclear Security at Stanford}

$\mathbf{R}$ od Ewing, a leading expert on nuclear materials, has been named the inaugural Frank Stanton Professor in Nuclear Security at the Center for Interna-

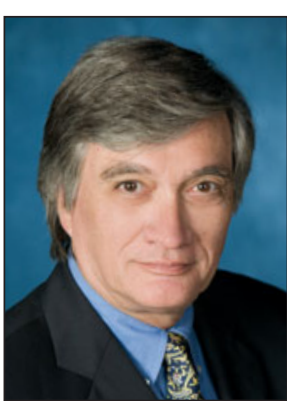
tional Security and Cooperation (CISAC)

Ewing has written extensively on issues relating to nuclear waste management and is Chair of the US Nuclear Waste Technical Review Board. He will have a joint appointment as Professor of
Geological and Environmental Sciences in the School of Earth Sciences and as a Senior Fellow at CISAC. He will begin his new position at Stanford in January.

"Given the very long and distinguished history of the Stanton Foundation's involvement in issues of nuclear security, this appointment provides me with a unique opportunity to blend science with security policy," Ewing said.

The endowed chair was recently established with a $\$ 5$ million gift to CISAC from the Stanton Foundation to aid the center in its long-standing mission to build a safer world through rigorous policy research in nuclear security.

Ewing, currently the Edward $\mathrm{H}$. Kraus Distinguished Professor in the Department of Earth \& Environmental Sciences at the University of Michigan, will conduct research on nuclear security and energy and related issues relevant to international arms control policy when he arrives at Stanford.

He will also teach a course at CISAC related to nuclear security issues. In his research at Stanford's School of Earth Sciences, Ewing will focus on the response of materials to extreme environments, and the demand for strategic minerals for use in the development of sustainable energy technologies.

Ewing received a BS degree in geology from Texas Christian University (1968, summa cum laude) and MS (1972) and $\mathrm{PhD}$ (1974, with distinction) degrees from Stanford University, where he held a Fellowship from the National Science Foundation. His honors include Fellow of the Geological Society of America, Mineralogical Society of America, American Geophysical Union, Geochemical Society, American Ceramic Society, the American Association for the Advancement of Science, and the Materials Research Society. Ewing's involvement in issues related to the nuclear fuel cycle has proceeded in parallel with the meetings of the Materials Research Society, where he has been a member of the program committee for the symposium on the Scientific Basis for Nuclear Waste Management held in 10 different countries over the past 35 years. 